\section{Cureus}

\title{
Improving C1-C2 Complex Fusion Rates: An Alternate Approach
}

Samer S. Ghostine ${ }^{1}$, Paul E. Kaloostian ${ }^{2}$, Christ Ordookhanian ${ }^{3}$, Sean W. Kaloostian ${ }^{4}$, Parham Zarrini ${ }^{5}$, Terrence Kim ${ }^{6}$, Stephen Scibelli ${ }^{7}$, Scott J. Clark-Schoeb ${ }^{8}$, Srinath Samudrala ${ }^{9}$, Carl Lauryssen ${ }^{10}$, Amandip S. Gill ${ }^{11}$, Patrick J. Johnson ${ }^{12}$

1. Neurological Surgery, University of California, Riverside School of Medicine 2. Neurological Surgery, University of California, Riverside School of Medicine, Riverside, USA 3. School of Medicine, University of California, Riverside, USA 4. Neurological Surgery, University of California, Irvine School of Medicine, Orange, USA 5. Cardiology, University of Miami, Medical School 6. Orthopedic Surgery, Cedars-Sinai Medical Center, los angeles, USA 7. Neurological Surgery, Memorial Neurospine, Jacksonville, USA 8. Spine Surgery, New Jersey Spine Center 9. Neurological Surgery, Pomona Valley Medical Center, Pomona, USA 10. Neurological Surgery, St. David's Round Rock Medical Center, Round Rock, USA 11. Neurological Surgery, Riverside Community Ho, Riverside, USA 12. Institute for Spinal Disorders, Cedars-Sinai Medical Center

$\square$ Corresponding author: Paul E. Kaloostian, pkaloostian@gmail.com Disclosures can be found in Additional Information at the end of the article

\section{Abstract}

The surgical repair of atlantoaxial instabilities (AAI) presents complex and unique challenges, originating from abnormalities and/or trauma within the junction regions of the $\mathrm{C} 1-\mathrm{C} 2$ atlasaxis, to surgeons. When this region is destabilized, surgical fusion becomes of key importance in order to prevent spinal cord injury. Several techniques can be utilized to provide for the adequate fusion of the atlantoaxial construct. Nevertheless, many individuals have less than ideal rates of fusion, below 35\%-40\%, which also involves the C2 nerve root being sacrificed. This suboptimal and unavoidable iatrogenic complication results in the elevated probability of complications typically composed of vertebral artery injury. This review is a retrospective analysis of 87 patients from Cedars Sinai Medical Center in Los Angeles, California, who had the C1-C2 surgical fusion procedure performed within the time frame from 2001 to 2008, with a mean follow-up period of three years. These patients had presented with typical AAI symptoms of fatigability, limited mobility, and clumsiness. Diagnosis of C1-C2 instability was documented via radiographic studies, typically utilizing computed tomography (CT) scans or xrays. All patients had bilateral C1 lateral masses and C2 pedicle screws. In addition, the C1-C2 joint was accessed by retracting the $\mathrm{C} 2$ nerve root superiorly and exposing the joint by utilizing a high-speed burr. The cavity that is developed within the joint is packed with local autologous bone from the cephalad resection of the C2 laminae. Fusion of the C1-C2 joint was achieved in all patients and a final follow-up was conducted approximately three years postoperative. Of the 87 patients, two presented with occipital headaches resulting from the $\mathrm{C} 1$ screws impinging on the $\mathrm{C} 2$ nerve root. The issue was rectified by removing instrumentation in both patients after documenting complete fusion via radiographic studies, with complete resolution of symptoms. No vertebral artery or spinal cord injuries were reported as a result of the minor complication. Overall, we aim to describe a safe and reliable alternative technique to fuse C1-C2 instability by focusing on intra-articular arthrodesis complementing instrumentation fixation. This methodology is advantageous from a biomechanical standpoint secondary to axial loading, as well as the large surface area available for arthrodesis. Additionally, this technique does not involve the resection of the C2 nerve root, resulting in low risk for vertebral artery or spinal cord injury. 
Categories: Neurology, Neurosurgery, Quality Improvement

Keywords: c1-c2, atlantoaxial, atlantoaxial fusion, aai, spinal instability, spinal instability, intraarticular, fusion, nerve root, atlas axis

\section{Introduction And Background}

Atlantoaxial instability (AAI) is a complex condition that must utilize surgical treatment to provide rigid fixation with a high rate of fusion (>95\%). Through the advancement of medical technology and the influx of new medical research, the surgeon's methodology of treatment is ever evolving, especially over the past few decades. Early on, stabilization of the C1-C2 complex (CCC) was achieved with instrumentation involving cable-graft wires that yielded suboptimal fusion rates without postoperative halo support [1-5]. Later on, Magerl and Seeman described the challenging C1-C2 transarticular screw stabilization, which yielded a satisfactory fusion rate without the need for a post-operative halo; however, a significant increase in the potential rate of surgical complication did arise, which included the risk of vertebral artery injury [6-20]. Subsequently, there are additional techniques that have been described in the literature, which involve a C1 transarticular screw combined with a C2 pedicle, pars interarticularis, or translaminar screws that can achieve an acceptable fusion rate without jeopardizing the rate of surgical success and minimizing postoperative complications [5,21-24]. Recently, a variant of the Harms and Goel technique was published in which C2 nerve roots were sacrificed bilaterally, allowing for the surgical insertion of an allograft spacer within the C1-C2 joint, while distracting a previously placed bilateral C1 lateral mass and C2 pedicle or pars interarticularis screws [25]. While this technique preferentially allows for a high rate of CCC fusion, there is a slight chance $(<34 \%)$ that postoperative occipital headaches can develop, which are associated with the $\mathrm{C} 2$ nerve root sacrifice. In our paper, we present a technique where we perform complete arthrodesis along the entire C1-C2 joint, complementing instrumentation fixation, without sacrificing the $\mathrm{C} 2$ nerve roots. Within the patients we treated, we report a $100 \%$ rate of fusion, but we do forewarn that our rate of fusion may deviate within larger patient sample sizes due to unmanipulable iatrogenic complicative variables and unforeseen surgical complications, which are present within all surgical practices.

\section{Review}

\section{Methods}

Case-Study Description

Within this retrospective study of 87 patients, all patients had some degree of C1-C2 complex instability. This retrospective study was conducted within one large academic center from 2001 to 2008 with Institutional Review Board approval. Each of these patients, to some degree (as mentioned earlier), had a form of C1-C2 instability, necessitating the need for C1-C2 stabilization and fusion. Indications frequently included, but were not restricted to os odontoideum (OO) and odontoid fractures, both acute and nonunion, C1-C2 instability, C2 mass formation, and traumatic $\mathrm{C} 1-\mathrm{C} 2$ fracture. These indications were evaluated through radiographic studies utilizing the professional expertise of a radiologist to review the various computed tomography (CT), x-ray, and magnetic resonance imaging (MRI) scans both preoperatively and postoperatively [22-27].

\section{Surgical Procedure Methodology}

Patients were positioned in the prone position and placed into the Mayfield head stabilization apparatus. The exposure of the $\mathrm{C} 1$ and $\mathrm{C} 2$ segments was accessed posteriorly and the $\mathrm{C} 2$ roots were bilaterally exposed and altered from anatomically normal positioning to reveal the C1-C2 joint without severing the nerve root. Partial laminectomy at the C2 joint was then completed 
and the spinous segment of the $\mathrm{C} 2$ was where the drilling occurred for the placement of a pedicle screw. The entirety of the complex was locked together by a rod system and screws. Utilizing a torque driver, all screws and rods were firmly locked into place together.

\section{Results}

Post-operative outcomes for all patients were verified through radiographical studies over a mean of three years and noted a 100\% rate of fusion, except for two patients who experienced postoperative complications and underwent additional surgical procedures [28]. Of the two reports of postoperative headaches, surgeons noted the cause was likely due to screw impingement on the $\mathrm{C} 2$ nerve root. In each of these cases, the screws were removed safely, with complete resolution of patient pain. In all cases, no spinal cord injury or vertebral artery injury was noted, along with no clinically significant manifestations of neurological deficits with any of these patients postoperatively, as determined by review of the clinical documentation [29]. The radiological studies conducted allowed for the interpretation of postoperative scans for the assessment of fusion and the integrity of instrumentation. Each patient was evaluated by a review of the clinical documentation within specific patient charts, and it was deduced that such a surgical procedure was indeed optimal and recommended among neurological surgeons, aided by radiological studies [30-35].

\section{Discussion}

\section{Evolution of the Atlantoaxial Fusion}

Preliminary descriptions of posterior atlantoaxial fusion were conducted by Gallie, which involved the placement of a notched bone graft between the posterior arch of C1 and the medial lamina and the spinous process of C2 [36]. This surgical construct was functionally limited due to its diminished ability to resist rotational stress, resulting in the need for a rigid postoperative orthosis. To provide enhanced rotational stability, Brooks performed bilateral, interlaminar bone grafts [1]. Within the two surgical procedures discussed, performed by Gallie and Brooks, bone grafts were secured by sublaminar wires between C1-C2. However, the placement of such sublaminar wires provided for an increased chance of injury to neural structures within the spinal canal. These suboptimal results and surgical complications prompted the development of novel techniques to replace the sublaminar wiring at C2 with a loop of wire around the C2 spinous region [2,37]. The Locksley intersegmental tie-bar technique added a posterior stabilization plate involving an additional wire joined to the posterior C1 and C2 spinous processes [36]. Along with the bilateral onlay grafts, this plate gave three-point fixation and greatly increased stabilization [38]. Interlaminar hooks, called Halifax clamps or Knot's rods, were developed by Tucker [39]. These interlaminar devices were used to secure bilateral interlaminar bone grafts similar to Brooks' fusion and did not require the passing of sublaminar wires. However, the dislodgment of the clamps was a frequently observed surgical complication, most likely attributed to the round shape of the posterior arch of C1. A halo orthosis was suggested to help prevent clamp dislodgment. When Magerl described the posterior transarticular screw, this was a major breakthrough for the field of neurosurgery, as it meant immediate and adequate stabilization of the fusion, replacing and rendering useless the need for postoperative external orthosis [36]. Like Barbour's anterior transarticular screw, this technique did not require intact posterior arches at C1 and C2, except in cases where a Gallietype bone graft and wiring was added to provide three-point fixation. Olerud et al. described an alternative method for providing three-point fixation by passing the transarticular screw through a plate that was attached to C1 by a claw [38]. More recently, Matsumoto supplemented the transarticular screws with autograft-containing titanium mesh cages, which were wired bilaterally in a manner similar to the Brooks method [39]. Today, bilateral polyaxial screws and rods are commonly used for atlantoaxial fusion, popularized by Harms and Melcher [16]. The screws are inserted into the lateral mass at C1 and the pedicles or pars at C2. Although 
structural grafting is not necessary, an onlay graft may be added to assist the fusion process. This technique has permitted C1-C2 instrumentation in patients with fixed C1-C2 subluxation and with an abnormal vertebral artery anatomy. However, C2 pedicle screws may violate the foramen transversarium, in which crossed translaminar C2 screws have been suggested as an alternative route [19].

\section{The C1-C2 Joint}

The C1-C2 articular joint distinguishes itself from the family of spinal joints by its integrating roles of intervertebral discs and facet joints of other spinal levels. It is horizontal and carries most of the head weight like all spinal intervertebral discs do. It is ventral to the spinal nerves and is able to assume a flexion-extension motion of 12 degrees like other cervical facet joints. However, unlike other spinal facet joints, it is capable of allowing for 47 degrees of rotational motion or $50 \%$ of the cervical spinal rotational motion capacity [20-21]. Being a small joint with a significant contribution to motion and agility, it is likely due to degenerative changes onset by the inflammatory pannus rheumatoid arthritis (RA), which ultimately lead to its instability. The instability of the joint is often clinically symptomatic, and a surgical fusion is warranted and, in most cases, necessary for the lividity of the patient [40-43].

\section{C1-C2 Arthrodesis}

Surgical fusion of mobile, unstable, or painful joints has been widely performed in the past and continues to be done; however, through the advancement of surgical technologies, former highly invasive techniques can be substituted by less invasive and overall better procedures. The fusion of the C1-C2 joint is routinely performed as a treatment of instability. Typically, in order to fuse the C1-C2 joint, spinal surgeons performed either an onlay fusion in the C1-C2 interlaminar space with or without the use of graft material or placed a graft in the interarticular C1-C2 joint in addition to instrumentation to immobilize the joint [1-2,20,44]. We describe complete arthrodesis at the CCC by the use of curettes and a high-speed drill. The curettes are used to identify the C1-C2 joints and allow for the removal of all cartilage along the joints [45]. A high-speed drill is used to then complete the arthrodesis at the CCC [46]. The subsequent removal of cartilage and roughing up of the CCC bilaterally allows for an increased fusion rate and acts as a scaffold for the placement of allograft and/or autograft material (Figures 1-3) in addition to the instrumentation at C1 and C2 bilaterally[47-50]. 


\section{Cureus}

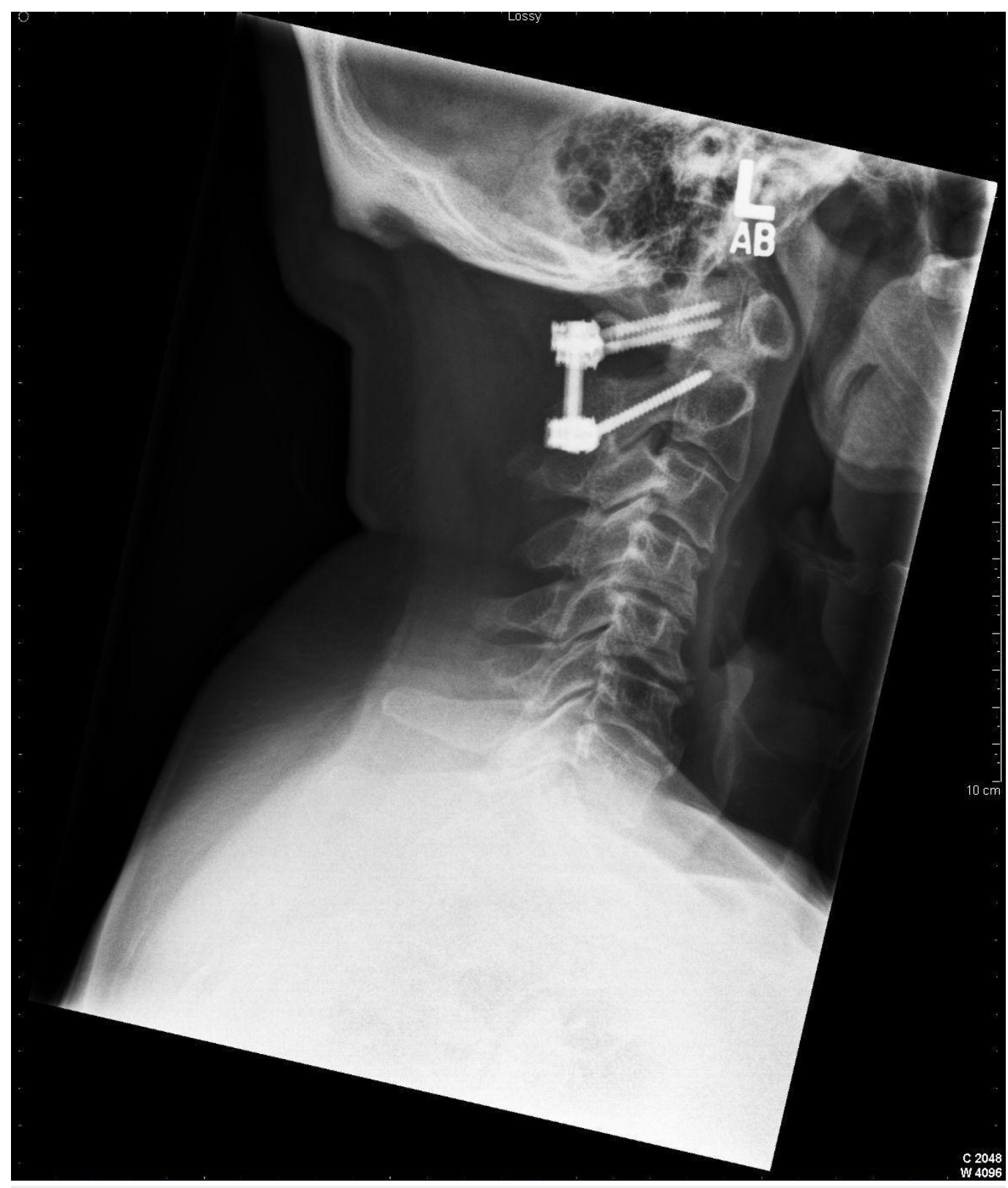

FIGURE 1: Example C1-C2 instrumentation is noted with appropriate placement of $\mathrm{C} 1$ lateral mass screws and $\mathrm{C} 2$ pedicle screws 


\section{Cureus}

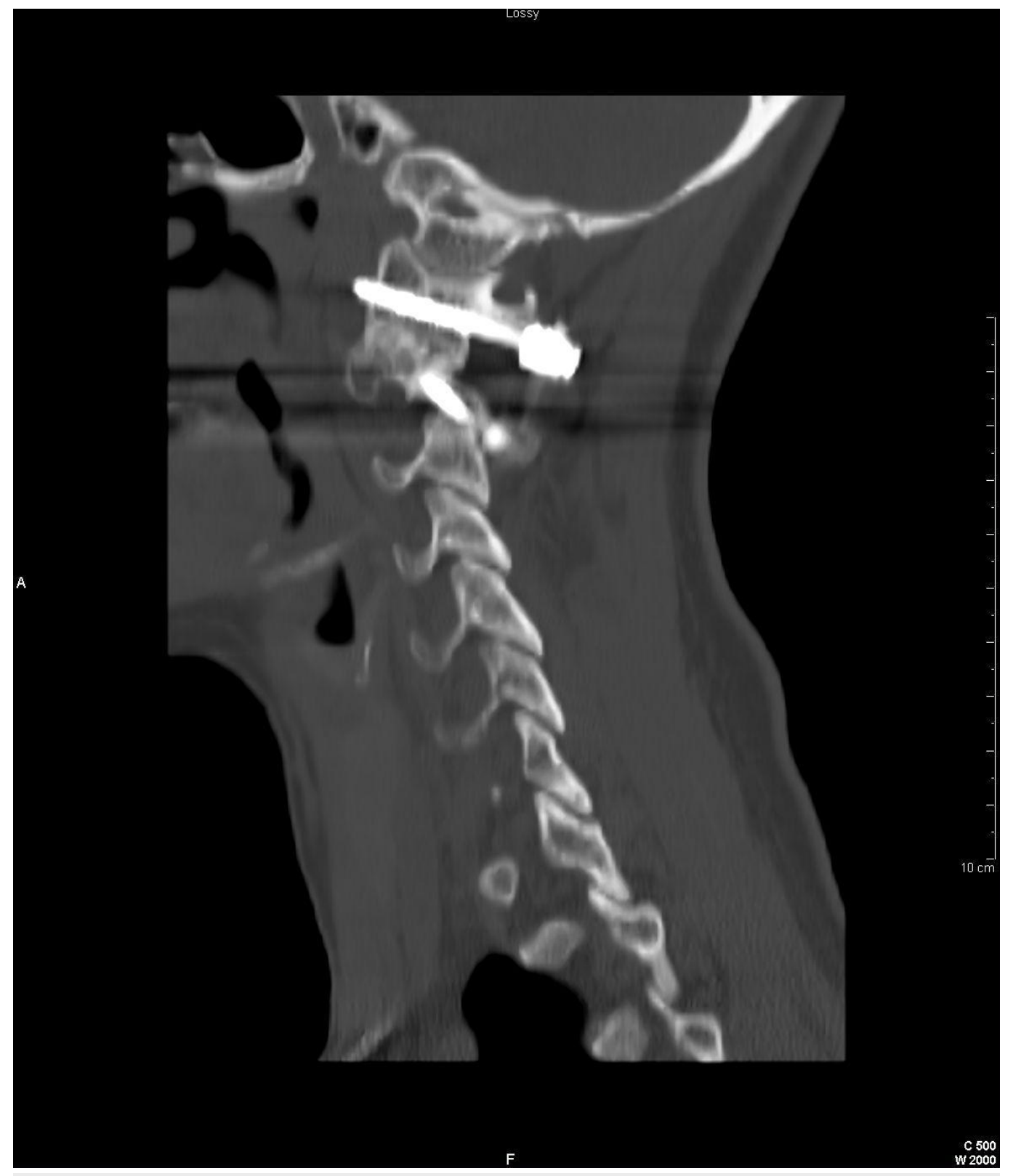

FIGURE 2: C1-C2 instrumentation with notable fusion, as seen by the bridging bony fusion mass post the arthrodesis of $\mathrm{C} 1$ C2 joints 


\section{Cureus}

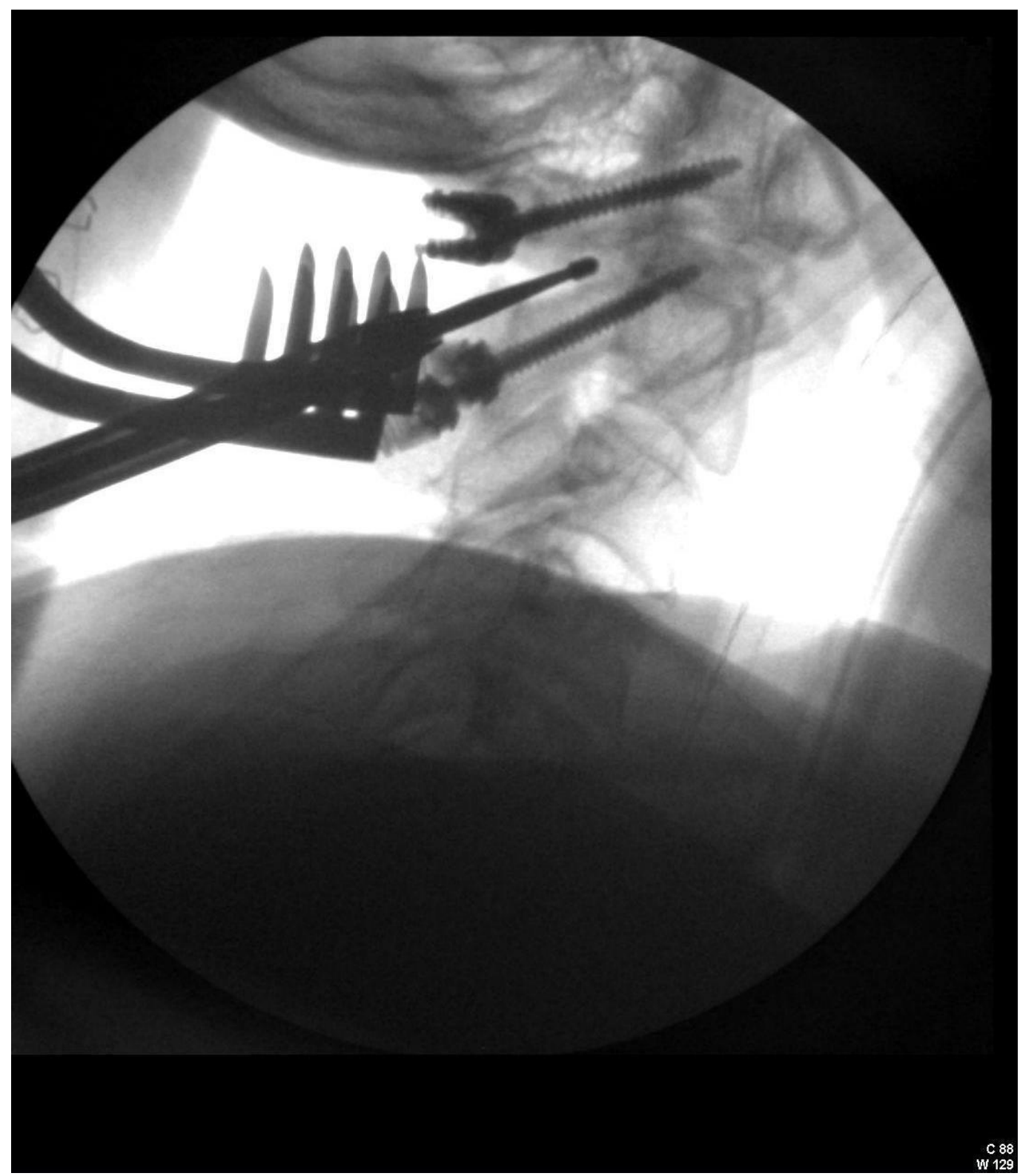

FIGURE 3: Intraoperative image post instrumentation as arthrodesis using high-speed drill is being performed along $\mathrm{C}_{1}$ and $\mathrm{C} 2$ as well as the joints between $\mathrm{C} 1$ and $\mathrm{C} 2$ bilaterally for fusion

\section{Conclusions}

Within our review, we describe an alternate surgical methodology that tremendously enhances the success rates of C1-C2 fusion. Our proposed methodology ensures a safe and reliable alternative technique to fuse the C1-C2 Complex (CCC) by performing an intraarticular arthrodesis. This is advantageous from a biomechanical standpoint secondary to axial loading and the large surface area available for arthrodesis. Additionally, this technique does not involve the resection of the $\mathrm{C} 2$ nerve root and results in low risks for vertebral artery or spinal cord injury. Overall, this is a method that we believe should be implemented in the skillset of every neurosurgeon when attempting a C1-C2 fusion. The tremendous outcomes and patient satisfaction far surpass the success rates of older methodologies. 


\section{Additional Information \\ Disclosures}

Conflicts of interest: In compliance with the ICMJE uniform disclosure form, all authors declare the following: Payment/services info: All authors have declared that no financial support was received from any organization for the submitted work. Financial relationships: All authors have declared that they have no financial relationships at present or within the previous three years with any organizations that might have an interest in the submitted work. Other relationships: All authors have declared that there are no other relationships or activities that could appear to have influenced the submitted work.

\section{Acknowledgements}

We would like to thank Helen Cambron and Maria Naylor for their assistance throughout the composition of this manuscript.

\section{References}

1. Brooks AL, Jenkins EB: Atlanto-axial arthrodesis by the wedge compression method. J Bone Joint Surg Am. 1978, 60:279-284.

2. Dickman CA, Sonntag VK, Papadopoulos SM, Hadley MN: The interspinous method of posterior atlantoaxial arthrodesis. J Neurosurg. 1991, 74:190-198. 10.3171/jns.1991.74.2.0190

3. Fried LC: Atlanto-axial fracture-dislocations. Failure of posterior C.1 to C.2 fusion. J Bone Joint Surg Br. 1973, 55:490-496.

4. Griswold DM, Albright JA, Schiffman E, Johnson R, Southwick W: Atlanto-axial fusion for instability. J Bone Joint Surg Am. 1978, 60:285-292.

5. Hoh DJ, Maya M, Jung A, Ponrartana S, Lauryssen CL: Anatomical relationship of the internal carotid artery to C- 1: clinical implications for screw fixation of the atlas. J Neurosurg Spine. 2008, 8:335-340. 10.3171/SPI/2008/8/4/335

6. Dickman CA, Sonntag VK: Posterior C1-C2 transarticular screw fixation for atlantoaxial arthrodesis. Neurosurgery. 1998, 43:275-280.

7. Gluf WM, Brockmeyer DL: Atlantoaxial transarticular screw fixation: a review of surgical indications, fusion rate, complications, and lessons learned in 67 pediatric patients. J

Neurosurg Spine. 2005, 2:164-169. 10.3171/spi.2005.2.2.0164

8. Gluf WM, Schmidt MH, Apfelbaum RI: Atlantoaxial transarticular screw fixation: a review of surgical indications, fusion rate, complications, and lessons learned in 191 adult patients. J Neurosurg Spine. 2005, 2:155-163. 10.3171/spi.2005.2.2.0155

9. Haid RW Jr: C1-C2 transarticular screw fixation: technical aspects . Neurosurgery. 2001, 49:71-74.

10. Henriques T, Cunningham BW, Olerud C, Shimamoto N, Lee GA, Larsson S, McAfee PA: Biomechanical comparison of five different atlantoaxial posterior fixation techniques . Spine (Phila Pa 1976). 2000, 25:2877-2883.

11. Crawford NR, Hurlbert RJ, Choi WG, Dickman CA: Differential biomechanical effects of injury and wiring at C1-C2. Spine (Phila Pa 1976). 1999, 24:1894-1902.

12. Dickman CA, Crawford NR, Paramore CG: Biomechanical characteristics of C1-2 cable fixations. J Neurosurg. 1996, 85:316-322. 10.3171/jns.1996.85.2.0316

13. Paramore CG, Dickman CA, Sonntag VK: The anatomical suitability of the C1-2 complex for transarticular screw fixation. J Neurosurg. 1996, 85:221-224. 10.3171/jns.1996.85.2.0221

14. Resnick DK, Benzel EC: C1-C2 pedicle screw fixation with rigid cantilever beam construct: case report and technical note. Neurosurgery. 2002, 50:426-428.

15. Yoshida M, Neo M, Fujibayashi S, Nakamura T: Comparison of the anatomical risk for vertebral artery injury associated with the C2-pedicle screw and atlantoaxial transarticular screw. Spine (Phila Pa 1976). 2006, 31:513-517. 10.1097/01.brs.0000224516.29747.52

16. Harms J, Melcher RP: Posterior C1-C2 fusion with polyaxial screw and rod fixation . Spine (Phila Pa 1976). 2001, 26:2467-2471.

17. Menendez JA, Wright NM: Techniques of posterior C1-C2 stabilization. Neurosurgery. 2007, 
60:103-111. 10.1227/01.NEU.0000249220.50085.E4

18. Wang MY: C2 crossing laminar screws: cadaveric morphometric analysis . Neurosurgery. 2006, 59:84-88. 10.1227/01.NEU.0000219900.24467.32

19. Wright NM: Posterior C2 fixation using bilateral, crossing C2 laminar screws: case series and technical note. J Spinal Disord Tech. 2004, 17:158-162.

20. Aryan HE, Newman CB, Nottmeier EW, Acosta FL, Jr., Wang VY, Ames CP: Stabilization of the atlantoaxial complex via C-1 lateral mass and C-2 pedicle screw fixation in a multicenter clinical experience in 102 patients: modification of the Harms and Goel techniques. J Neurosurg Spine. 2008, 8:222-229. 10.3171/SPI/2008/8/3/222

21. Sen MK, Steffen T, Beckman L, Tsantrizos A, Reindl R, Aebi M: Atlantoaxial fusion using anterior transarticular screw fixation of C1-C2: technical innovation and biomechanical study. Eur Spine J. 2005, 14:512-518. 10.1007/s00586-004-0823-0

22. Fiore AJ, Haid RW, Rodts GE, Subach BR, Mummaneni PV, Riedel CJ, Birch BD: Atlantal lateral mass screws for posterior spinal reconstruction: technical note and case series. Neurosurg Focus. 2002, 12:5.

23. Coyne TJ, Fehlings MG, Wallace MC, Bernstein M, Tator $\mathrm{CH}$ : C1-C2 posterior cervical fusion: long-term evaluation of results and efficacy. Neurosurgery. 1995, 37:688-692.

24. Jeanneret B, Magerl F: Primary posterior fusion C1/2 in odontoid fractures: indications, technique, and results of transarticular screw fixation. J Spinal Disord. 1992, 5:464-475.

25. Stillerman CB, Wilson JA: Atlanto-axial stabilization with posterior transarticular screw fixation: technical description and report of 22 cases. Neurosurgery. 1993, 32:948-954.

26. Kuroki H, Rengachary SS, Goel VK, Holekamp SA, Pitkanen V, Ebraheim NA: Biomechanical comparison of two stabilization techniques of the atlantoaxial joints: transarticular screw fixation versus screw and rod fixation. Neurosurgery. 2005, 56:151-159.

27. Melcher RP, Puttlitz CM, Kleinstueck FS, Lotz JC, Harms J, Bradford DS: Biomechanical testing of posterior atlantoaxial fixation techniques. Spine (Phila Pa 1976). 2002, 27:24352440 .

28. Richter M, Schmidt R, Claes L, Puhl W, Wilke HJ: Posterior atlantoaxial fixation: biomechanical in vitro comparison of six different techniques. Spine (Phila Pa 1976). 2002, 27:1724-1732.

29. Spangenberg P, Coenen V, Gilsbach JM, Rohde V: Virtual placement of posterior C1-C2 transarticular screw fixation. Neurosurg Rev. 2006, 29:114-117. 10.1007/s10143-005-0003-7

30. Jun BY: Anatomic study for ideal and safe posterior C1-C2 transarticular screw fixation . Spine (Phila Pa 1976). 1998, 23:1703-1707.

31. Blagg SE, Don AS, Robertson PA: Anatomic determination of optimal entry point and direction for C1 lateral mass screw placement. J Spinal Disord Tech. 2009, 22:233-239. 10.1097/BSD.0b013e31817ff95a

32. Lee SH, Kim ES, Sung JK, Park YM, Eoh W: Clinical and radiological comparison of treatment of atlantoaxial instability by posterior C1-C2 transarticular screw fixation or C1 lateral massC2 pedicle screw fixation. J Clin Neurosci. 2010, 17:886-892. 10.1016/j.jocn.2009.10.008

33. Tan J, Li L, Sun G, et al.: C1 lateral mass-C2 pedicle screws and crosslink compression fixation for unstable atlas fracture. Spine (Phila Pa 1976). 2009, 34:2505-2509. 10.1097/BRS.0b013e3181b4009a

34. Calisaneller T, Yilmaz C, Ozdemir O, Caner H: Posterior atlantal lateral mass fixation technique with polyaxial screw and rod fixation system. Turk Neurosurg. 2008, 18:142-148.

35. Tan J, Ni CH, Li LJ, Zhou W, Qian L: C1 lateral mass-C2 pedicle screws and crosslink compression fixation for instable atlas fracture [Article in Chinese]. Zhonghua Yi Xue Za Zhi. 2006, 86:1743-1747.

36. Gallie WE: Skeletal traction in the treatment of fractures and dislocations of the cervical spine. Ann Surg. 1937, 106:770-776.

37. Huang DG, Hao DJ, He BR, et al.: Posterior atlantoaxial fixation: a review of all techniques . Spine J. 2015, 15:2271-2281. 10.1016/j.spinee.2015.07.008

38. Vender JR, Houle PJ, Harrison S, McDonnell DE: Occipital-cervical fusion using the Locksley intersegmental tie bar technique: long-term experience with 19 patients. Spine J. 2002, 2:134141.

39. Tucker HH: Technical report: method of fixation of subluxed or dislocated cervical spine below C1-C2. Can J Neurol Sci. 1975, 2:381-382.

40. Schaller B, Huang KY, Lin RM, Fang JJ: A novel method of C1-C2 transarticular screw 
insertion for symptomatic atlantoaxial instability using a customized guiding block: A case report and a technical note. Medicine (Baltimore). 2016, 95:5100.

10.1097/MD.0000000000005100

41. Zheng Y, Hao D, Wang B, He B, Hu H, Zhang $\mathrm{H}$ : Clinical outcome of posterior C1-C2 pedicle screw fixation and fusion for atlantoaxial instability: a retrospective study of 86 patients. J

Clin Neurosci. 2016, 32:47-50. 10.1016/j.jocn.2015.12.045

42. Jeong JH, Kim HK, Im SB: Surgical management for destructive atlantoaxial spondyloarthropathy in long-term hemodialysis patients. World Neurosurg. 2017, 97:757753. 10.1016/j.wneu.2016.10.054

43. Ryu JI, Bak KH, Kim JM, Chun HJ: Comparison of transarticular screw fixation and C1 lateral mass-C2 pedicle screw fixation in patients with rheumatoid arthritis with atlantoaxial instability. World Neurosurg. 2017, 99:179-185. 10.1016/j.wneu.2016.12.028

44. Wang S, Wang C, Wood KB, Yan M, Zhou H: Radiographic evaluation of the technique for C1 lateral mass and C2 pedicle screw fixation in three hundred nineteen cases. Spine (Phila Pa 1976). 2011, 36:3-8. 10.1097/BRS.0b013e3181c97dc7

45. Huang DG, Hao DJ, Li GL, Guo H, Zhang YC, He BR: C2 nerve dysfunction associated with C1 lateral mass screw fixation. Orthop Surg. 2014, 6:269-273. 10.1111/os.12136

46. Kotil K, Bilgili MG, Kayaci S: Reduction and arthrodesis with sublaminar spiral silk in atlantoaxial joint instability. Acta Orthop Traumatol Turc. 2014, 48:443-448. 10.3944/AOTT.2014.3156

47. Hood B, Hamilton DK, Smith JS, Dididze M, Shaffrey C, Levi AD: The use of allograft and recombinant human bone morphogenetic protein for instrumented atlantoaxial fusions. World Neurosurg. 2014, 82:1369-1373. 10.1016/j.wneu.2013.01.083

48. Godzik J, Ravindra VM, Ray WZ, Schmidt MH, Bisson EF, Dailey AT: Comparison of structural allograft and traditional autograft technique in occipitocervical fusion: radiological and clinical outcomes from a single institution. J Neurosurg Spine. 2015, 23:144-152. 10.3171/2014.12.SPINE14535

49. Elliott RE, Morsi A, Frempong-Boadu A, Smith ML: Is allograft sufficient for posterior atlantoaxial instrumented fusions with screw and rod constructs? A structured review of literature. World Neurosurg. 2012, 78:326-338. 10.1016/j.wneu.2011.12.083

50. Kakarla UK, Valdivia JV, Sonntag VK, Bambakidis NC: Intracranial hemorrhage and spinal cord injury from a fractured C1-C2 sublaminar cable: case report. Neurosurgery. 2010, 66:12031204. 10.1227/01.NEU.0000369198.70959.E1 